\title{
Synthesis of New Thiophene Derivatives and Their Use as Photostabilizers for Rigid Poly(vinyl chloride)
}

\author{
Asim A. Balakit, ${ }^{1}$ Ahmed Ahmed, ${ }^{2}$ Gamal A. El-Hiti, ${ }^{3}$ \\ Keith Smith, ${ }^{4}$ and Emad Yousif ${ }^{2}$ \\ ${ }^{1}$ College of Pharmacy, Babylon University, Babylon, Iraq \\ ${ }^{2}$ Department of Chemistry, College of Science, Al-Nahrain University, Baghdad, Iraq \\ ${ }^{3}$ Cornea Research Chair, Department of Optometry, College of Applied Medical Sciences, King Saud University, \\ P.O. Box 10219, Riyadh 11433, Saudi Arabia \\ ${ }^{4}$ School of Chemistry, Cardiff University, Main Building, Park Place, Cardiff CF10 3AT, UK \\ Correspondence should be addressed to Gamal A. El-Hiti; gelhiti@ksu.edu.sa
}

Received 23 September 2014; Revised 16 December 2014; Accepted 19 December 2014

Academic Editor: Qinglin Wu

Copyright (C) 2015 Asim A. Balakit et al. This is an open access article distributed under the Creative Commons Attribution License, which permits unrestricted use, distribution, and reproduction in any medium, provided the original work is properly cited.

Five new thiophenes, namely, $N$-[(3-bromo-2-methylthiophen-5-yl)methylene]-4-methoxyaniline (4a), $N$-[(3-bromo-2-methylthiophen-5-yl)methylene]-3,4-dimethoxyaniline (4b), $N$-[(3-bromo-2-methylthiophen-5-yl)methylene]-3,4-dimethylaniline (4c), 3-[(3-bromo-2-methylthiophen-5-yl)methyleneamino]-2-methylquinazolin-4(3H)-one (4d), and 3-[(3-bromo-2-methylthiophen-5-yl)methyleneamino]-2-isopropylquinazolin-4(3H)-one (4e), have been synthesized. All of these materials brought about a reduction in the level of photodegradation of poly(vinyl chloride) (PVC) films containing the synthesized thiophenes (0.5\%; by weight). The results obtained showed that the extent of photostabilization of PVC in the presence of an additive was in the order $4 e>4 d>4 b>4 a>4 c$. For the most favorable additive (4e), the rate of appearance of infrared absorption bands of degradation products was reduced by around two-thirds, while the quantum yield of chain scission was calculated to be reduced by a factor of more than one thousand. It is suggested that the additives may help stabilize PVC by direct absorption of UV radiation and dissipation of the energy as heat or that electrostatic attraction between the additives and PVC may assist transfer of energy from excited state PVC to the additive, from where it can be dissipated.

\section{Introduction}

Poly(vinyl chloride) (PVC) is second to polyethylene among the highest selling types of plastic materials, which are widely used in a wide range of industries including architecture, electronics, packaging, and transportation [1]. However, low photostability of PVC leads to hydrogen chloride loss, discoloration, and finally serious corrosion phenomena, accompanied by changes of physical and chemical properties of the PVC. The low cost and the good performance of PVC products have increased the utilization of this polymer in building, mainly in exterior applications such as window profiles and cladding [2]. However, ultimate user acceptance of the PVC products for outdoor building applications depends on their ability to resist photodegradation over long periods of sunlight exposure. To ensure weatherability, the PVC resin needs to be compounded and processed properly using suitable additives, leading to a complex material whose behavior and properties are quite different from those of the PVC resin itself [3]. Because of this, it is important to perform reliable weathering methods to test factors, like light and temperature, which influence the degradation of PVC based materials in accelerated service conditions. Due to the growing importance of the PVC, various studies have been reported that deal with the rheological behavior and mechanical properties of its blends [4], the properties of $\mathrm{PVC} /$ thermoplastic polyester elastomer blend systems [5], and fabrication of new antimicrobial PVC plastic [6]. The 
effect of UV light on the molecular structure of the PVC is an important issue that has attracted the attention of researchers [7].

As part of on-going research on the synthesis of polymeric materials [8], lithiation reactions [9], and the synthesis of various substituted heteroaromatic compounds [10] and on the stabilization of polymers [11], we became interested in the synthesis of thiophene derivatives. Here we report the syntheses of various imines derived from thiophenes, namely, $N$-[(3-bromo-2-methylthiophen-5-yl)methylene]-4-methoxyaniline (4a), N-[(3-bromo-2-methylthiophen-5-yl)methylene]-3,4-dimethoxyaniline (4b), N-[(3bromo-2-methylthiophen-5-yl)methylene]-3,4-dimethylaniline (4c), 3-[(3-bromo-2-methylthiophen-5-yl)methyleneamino]-2-methylquinazolin-4(3H)-one (4d), and 3-[(3bromo-2-methylthiophen-5-yl)methyleneamino]-2-isopropylquinazolin-4(3H)-one (4e) and studies of their activity in the photostabilization of PVC. To the best of our knowledge this is the first attempt to investigate the photostabilization of PVC films containing such compounds.

\section{Experimental}

2.1. General. Bromine-lithium exchange reactions were performed under an inert atmosphere. Glassware was oven dried, assembled hot, and allowed to cool under a stream of nitrogen gas. All chemicals and reagents were purchased from commercial sources and used without further purification. THF was distilled from sodium benzophenone ketyl and other solvents were purified by standard procedures [12]. IR spectra were recorded as $\mathrm{KBr}$ discs for solid materials or by applying droplets of liquid materials on a $\mathrm{NaCl}$ plate. ${ }^{1} \mathrm{H}$ and ${ }^{13} \mathrm{C}$ NMR spectra were recorded on a spectrometer operating at $400 \mathrm{MHz}$ for ${ }^{1} \mathrm{H}$ and $100 \mathrm{MHz}$ for ${ }^{13} \mathrm{C}$ measurements, respectively. Chemical shifts $\delta$ are reported in parts per million (ppm) relative to tetramethylsilane (TMS). Low- and high-resolution mass spectra were recorded on a time-offight mass spectrometer using electron impact (EI). Column chromatography was carried out using Fischer Scientific silica 60A (35-70 micron). $n$-Butyllithium was obtained from Aldrich Chemical Company and was estimated prior to use by the method of Watson and Eastham [13].

2.2. Synthesis of 3,5-Dibromo-2-methylthiophene (2). A solution of bromine $(12.00 \mathrm{~mL}, 37.20 \mathrm{~g}, 232.8 \mathrm{mmol})$ in acetic acid $(16 \mathrm{~mL})$ was added in a dropwise manner over $10 \mathrm{~min}$ to a stirred solution of 2-methylthiophene (1; $9.82 \mathrm{~g}, 100.0 \mathrm{mmol})$ in acetic acid $(40 \mathrm{~mL})$ at $\left(0^{\circ} \mathrm{C}\right)$. The reaction mixture was stirred at $0^{\circ} \mathrm{C}$ for $2 \mathrm{~h}$ and at room temperature for $16 \mathrm{~h}$. The mixture was quenched with water $(20 \mathrm{~mL})$ and solid $\mathrm{Na}_{2} \mathrm{CO}_{3}$ was then added to bring the $\mathrm{pH}$ to $\geq 9$. The product was extracted with $\mathrm{Et}_{2} \mathrm{O}(3 \times 60 \mathrm{~mL})$ and the combined organic extracts were dried $\left(\mathrm{MgSO}_{4}\right)$. The solvent was removed under reduced pressure to give the crude product as a reddish liquid, which was purified by distillation under reduced pressure to give pure 2 (23.04 g, $90.0 \mathrm{mmol} ; 90 \%)$ as a colorless oil (lit. [14] colorless oil). ${ }^{1} \mathrm{H}$ NMR $\left(400 \mathrm{MHz}, \mathrm{CDCl}_{3}\right) \delta: 6.87(\mathrm{~s}, 1 \mathrm{H})$ and $2.36(\mathrm{~s}, 3 \mathrm{H}) .{ }^{13} \mathrm{C} \mathrm{NMR}\left(100 \mathrm{MHz}, \mathrm{CDCl}_{3}\right) \delta: 136.0,131.9$,
108.8, 108.6, and 14.9. EI-MS $(m / z, \%): 258\left(\left[\mathrm{M}^{81} \mathrm{Br}_{2}\right]^{+}, 62\right)$, 257 (30), $256\left(\left[\mathrm{M}^{81} \mathrm{Br}^{79} \mathrm{Br}\right]^{+} 98\right), 255(60), 254\left(\left[\mathrm{M}^{79} \mathrm{Br}_{2}\right]^{+}\right.$, 80), 253 (32), 175 (100) and 96 (84). HRMS (EI): Calcd for $\mathrm{C}_{5} \mathrm{H}_{4} \mathrm{Br}_{2} \mathrm{~S}\left[\mathrm{M}^{79} \mathrm{Br}_{2}\right]^{+}$253.8409; found, 253.8400. FTIR ( $\nu_{\max }$, $\left.\mathrm{cm}^{-1}\right)$ : 3097, 2918, 1534, 1449 and 1305 .

\subsection{Synthesis of 3-Bromo-2-methylthiophene-5-carboxaldehy-} de (3). A solution of $n$-butyllithium $(64.0 \mathrm{~mL}, 1.60 \mathrm{M}$; $64.0 \mathrm{mmol}$ ) in hexane was added in a dropwise manner over 5 min to a stirred solution of 3,5-dibromo-2-methylthiophene $(2 ; 16.0 \mathrm{~g}, 62.5 \mathrm{mmol})$ in anhydrous THF $(100 \mathrm{~mL})$ at $-78^{\circ} \mathrm{C}$ under nitrogen. The solution turned orange then greenish yellow and finally yellowish orange. The reaction mixture was stirred at $-78^{\circ} \mathrm{C}$ for $30 \mathrm{~min}$ and DMF $(4.80 \mathrm{~g}, 65.7 \mathrm{mmol})$ was then added. The cooling bath was removed and the mixture was stirred at room temperature for $16 \mathrm{~h}$. The mixture was quenched with aqueous $\mathrm{HCl}(20 \mathrm{~mL}, 2 \mathrm{M})$ and the product was extracted with $\mathrm{Et}_{2} \mathrm{O}(3 \times 100 \mathrm{~mL})$. The organic layer was washed with saturated aqueous $\mathrm{NaHCO}_{3}$ solution $(100 \mathrm{~mL})$ and brine $(100 \mathrm{~mL})$ and then dried $\left(\mathrm{MgSO}_{4}\right)$. The solvent was removed under reduced pressure to give pure 3 (10.88 g, $53.05 \mathrm{mmol}$; $85 \%)$ as a yellow solid, m.p. $56-57^{\circ} \mathrm{C}$ (lit. $57-$ $58^{\circ} \mathrm{C}$ ) [15]. ${ }^{1} \mathrm{H} \mathrm{NMR}\left(400 \mathrm{MHz}, \mathrm{CDCl}_{3}\right) \delta$ (ppm): $9.69(\mathrm{~s}, 1 \mathrm{H})$, $7.51(\mathrm{~s}, 1 \mathrm{H})$ and $2.41(\mathrm{~s}, 3 \mathrm{H}) .{ }^{13} \mathrm{C} \mathrm{NMR}\left(100 \mathrm{MHz}, \mathrm{CDCl}_{3}\right) \delta$ (ppm): 181.6, 145.9, 140.1, 138.8, 111.3 and 15.9. EI-MS $(\mathrm{m} / z, \%)$ : $206\left(\left[\mathrm{M}^{81} \mathrm{Br}\right]^{+}, 75\right], 205(98), 204\left(\left[\mathrm{M}^{79} \mathrm{Br}\right]^{+}, 77\right), 203(100)$, 177 (25), 125 (20), 96 (40), 84 (32) and 69 (49). HRMS (EI): Calcd for $\mathrm{C}_{6} \mathrm{H}_{4} \mathrm{BrOS}\left[\mathrm{M}^{79} \mathrm{Br}, 1\right]^{+}$202.9172; found, 202.9166. $\operatorname{FTIR}\left(\nu_{\max }, \mathrm{cm}^{-1}\right): 3080,2859,1678$ and 1521.

2.4. Synthesis of Imines $\mathbf{4 a}-\boldsymbol{e}$. In a $10 \mathrm{~mL}$ microwave vial charged with a magnetic bar, 3-bromo-2-methylthiophene5 -carboxaldehyde $(3 ; 0.30 \mathrm{~g}, 1.46 \mathrm{mmol})$ and the appropriate amine $(1.46 \mathrm{mmol})$ were dissolved in absolute methanol $(6 \mathrm{~mL})$ and a drop of $\mathrm{HCl}$ was added to the mixture. The vial was sealed and subjected to microwave irradiation at $100^{\circ} \mathrm{C}$ for $5 \mathrm{~min}$. The mixture was cooled and then decanted into a $50 \mathrm{~mL}$ round bottomed flask and the solvent was evaporated under reduced pressure. The solid crude product was recrystallized from ethanol to give the desired product.

2.4.1. N-[(3-Bromo-2-methylthiophen-5-yl)methylene]-4-methoxyaniline $(4 a)$. Produced from 4-methoxyaniline $(0.18 \mathrm{~g}$, $1.46 \mathrm{mmol}$ ); yield: $0.41 \mathrm{~g}, 1.32 \mathrm{mmol}$; $91 \%$; m.p. $73-74^{\circ} \mathrm{C}$. ${ }^{1} \mathrm{H}$ NMR $\left(400 \mathrm{MHz}, \mathrm{CDCl}_{3}\right) \delta: 8.36(\mathrm{~s}, 1 \mathrm{H}), 7.20-7.10(\mathrm{~m}$, $4 \mathrm{H}), 6.83(\mathrm{~s}, 1 \mathrm{H}), 3.76(\mathrm{~s}, 3 \mathrm{H})$, and $2.38(\mathrm{~s}, 3 \mathrm{H}) .{ }^{13} \mathrm{C} \mathrm{NMR}$ $\left(100 \mathrm{MHz}, \mathrm{CDCl}_{3}\right) \delta: 158.5,149.6,143.8,139.8,139.4,133.8$, $122.4,114.4,109.9,55.5$, and 15.5. EI-MS $(\mathrm{m} / z, \%): 311$ $\left(\left[\mathrm{M}^{81} \mathrm{Br}\right]^{+}, 88\right), 309\left(\left[\mathrm{M}^{79} \mathrm{Br}\right]^{+}, 90\right), 296(97), 294(100), 86$ (51), 84 (96). HRMS (EI): calcd. for $\mathrm{C}_{13} \mathrm{H}_{12} \operatorname{BrNOS}\left[\mathrm{M}^{79} \mathrm{Br}\right]^{+}$ 308.9823; found, 308.9825. FTIR $\left(\nu_{\max }, \mathrm{cm}^{-1}\right)$ : 2960, 2836, $1614,1505,1469$.

2.4.2. N-[(3-Bromo-2-methylthiophen-5-yl)methylene]-3,4-dimethoxyaniline (4b). Produced from 3,4-dimethoxyaniline (0.224 g, $1.46 \mathrm{mmol})$; yield: $0.44 \mathrm{~g}, 1.30 \mathrm{mmol}$; $89 \%$; m.p. $118-$ $119^{\circ} \mathrm{C} .{ }^{1} \mathrm{H}$ NMR $\left(400 \mathrm{MHz}, \mathrm{CDCl}_{3}\right) \delta: 8.47(\mathrm{~s}, 1 \mathrm{H}), 7.28(\mathrm{~s}, 1 \mathrm{H})$, 6.90-6.81 (m, 3H), $3.94(\mathrm{~s}, 3 \mathrm{H}), 3.92(\mathrm{~s}, 3 \mathrm{H})$, and $2.48(\mathrm{~s}, 3 \mathrm{H})$. 
${ }^{13} \mathrm{C} \mathrm{NMR}\left(100 \mathrm{MHz}, \mathrm{CDCl}_{3}\right) \delta: 150.0,149.3,147.9,144.2,139.7$, $139.6,134.0,112.1,111.2,110.0,105.8,56.1,55.9$, and 15.52. EI-MS $(\mathrm{m} / z, \%): 341\left(\left[\mathrm{M}^{81} \mathrm{Br}\right]^{+}, 53\right), 339\left(\left[\mathrm{M}^{79} \mathrm{Br}\right]^{+}, 54\right), 326(51), 324$ (54), 86 (94), 84 (100). HRMS (EI): calcd. for $\mathrm{C}_{14} \mathrm{H}_{14} \mathrm{BrNO}_{2} \mathrm{~S}$ $\left[\mathrm{M}^{79} \mathrm{Br}\right]^{+}$338.9929; found 338.9924. FTIR $\left(\nu_{\max }, \mathrm{cm}^{-1}\right): 2998$, 2933, 2833, 1612, 1587, 1510.

2.4.3. N-[(3-Bromo-2-methylthiophen-5-yl)methylene]-3,4dimethylaniline (4c). Produced from 3,4-dimethylaniline $(0.177 \mathrm{~g}, 1.46 \mathrm{mmol})$; yield: $0.40 \mathrm{~g}, 1.30 \mathrm{mmol}$; $89 \%$; m.p. 51$52^{\circ} \mathrm{C} .{ }^{1} \mathrm{H}$ NMR $\left(400 \mathrm{MHz}, \mathrm{CDCl}_{3}\right) \delta: 8.34(\mathrm{~s}, 1 \mathrm{H}), 7.19(\mathrm{~s}, 1 \mathrm{H})$, 7.10-6.90 (m, 3H), 2.38 (s, 3H), 2.21 (s, 3H), and $2.19(\mathrm{~s}, 3 \mathrm{H})$. ${ }^{13} \mathrm{C}$ NMR $\left(100 \mathrm{MHz}, \mathrm{CDCl}_{3}\right) \delta: 150.7,148.7,139.8,139.6,137.4$, $134.9,133.9,130.3,122.5,118.2,109.9,19.9,19.4$, and 15.5. EI-MS $(m / z, \%): 309\left(\left[\mathrm{M}^{81} \mathrm{Br}\right]^{+}, 46\right), 308(32), 307\left(\left[\mathrm{M}^{79} \mathrm{Br}\right]^{+}, 47\right)$, 306 (24), 206 (41), 205 (44), 204 (33), 203 (42), 86 (64), 84 (100). HRMS (EI): calcd. for $\mathrm{C}_{14} \mathrm{H}_{14} \mathrm{Br} \mathrm{NS}\left[\mathrm{M}^{79} \mathrm{Br}\right]^{+}$307.0030; found, 307.0029. FTIR $\left(\nu_{\max }, \mathrm{cm}^{-1}\right): 3084,3014,2966,2917$, $1615,1591$.

2.4.4. 3-[(3-Bromo-2-methylthiophen-5-yl)methyleneamino]2-methylquinazolin-4(3H)-one (4d). Produced from 3amino-2-methylquinazolin-4(3H)-one $(0.256 \mathrm{~g}, 1.46 \mathrm{mmol})$. Yield: $0.48 \mathrm{~g}, 1.33 \mathrm{mmol}$; $91 \%$; m.p. $231-232^{\circ} \mathrm{C} .{ }^{1} \mathrm{H}$ NMR $\left(400 \mathrm{MHz}, \mathrm{CDCl}_{3}\right) \delta: 9.12(\mathrm{~s}, 1 \mathrm{H}, \mathrm{CH}), 8.22(\mathrm{~d}, J=9.0 \mathrm{~Hz}$, $1 \mathrm{H}), 7.72-7.66(\mathrm{~m}, 1 \mathrm{H}), 7.60(\mathrm{~d}, J=8 \mathrm{~Hz}, 1 \mathrm{H}), 7.40$ (app. $\mathrm{t}, J=$ $8.0 \mathrm{~Hz}, 1 \mathrm{H}), 7.20(\mathrm{~s}, 1 \mathrm{H}), 2.60\left(\mathrm{~s}, 3 \mathrm{H}, \mathrm{CH}_{3}\right)$, and $2.42(\mathrm{~s}, 3 \mathrm{H}$, $\left.\mathrm{CH}_{3}\right) .{ }^{13} \mathrm{C} \mathrm{NMR}\left(100 \mathrm{MHz}, \mathrm{CDCl}_{3}\right) \delta: 159.1,157.4,154.2,146.3$, $141.3,136.3,134.6,134.5,127.2,126.9,126.5,121.4,110.5,22.9$, and 15.6. EI-MS $(m / z, \%): 363\left(\left[\mathrm{M}^{81} \mathrm{Br}\right]^{+}, 8\right), 361\left(\left[\mathrm{M}^{79} \mathrm{Br}\right]^{+}\right.$, 9), 203 (100), 160 (98), 122 (97), 86 (92), 84 (94), 70 (88). HRMS (EI): calcd. for $\mathrm{C}_{15} \mathrm{H}_{12} \mathrm{Br} \mathrm{N} \mathrm{N}_{3} \mathrm{OS}\left[\mathrm{M}^{79} \mathrm{Br}\right]^{+} 360.9884$; found, 360.9877. FTIR $\left(\nu_{\max }, \mathrm{cm}^{-1}\right): 2917,1673,1601,1568$.

2.4.5. 3-[(3-Bromo-2-methylthiophen-5-yl)methyleneamino]2-isopropylquinazolin-4(3H)-one (4e). Produced from 3-amino-2-isopropylquinazolin-4(3H)-one $(0.297 \mathrm{~g}, 1.46 \mathrm{mmol})$. Yield: $0.50 \mathrm{~g}, 1.28 \mathrm{mmol}$; $88 \%$; m.p. $165-166^{\circ} \mathrm{C} .{ }^{1} \mathrm{H}$ NMR $\left(400 \mathrm{MHz}, \mathrm{CDCl}_{3}\right) \delta: 9.15(\mathrm{~s}, 1 \mathrm{H}), 8.28(\mathrm{~d}, J=8 \mathrm{~Hz}, 1 \mathrm{H})$, $7.78-7.76(\mathrm{~m}, 2 \mathrm{H}), 7.51-7.45(\mathrm{~m}, 1 \mathrm{H}), 7.36(\mathrm{~s}, 1 \mathrm{H}), 3.57$ (sept, $J=7 \mathrm{~Hz}, 1 \mathrm{H}), 2.51(\mathrm{~s}, 3 \mathrm{H})$, and $1.40(\mathrm{~d}, J=7 \mathrm{~Hz}, 6 \mathrm{H}) .{ }^{13} \mathrm{C}$ NMR $\left(100 \mathrm{MHz}, \mathrm{CDCl}_{3}\right) \delta: 160.6,159.4,158.1,141.4,136.2$, $134.7,134.4,127.2,127.2,126.6,121.1,110.5,32.0,20.4$, and 15.6 (one quaternary carbon signal was of insufficient intensity to allow confident discrimination from noise, but may have been at $147.8 \mathrm{ppm})$. EI-MS $(m / z, \%): 391\left(\left[\mathrm{M}^{81} \mathrm{Br}\right]^{+}, 32\right), 389$ $\left(\left[\mathrm{M}^{79} \mathrm{Br}\right]^{+}, 39\right), 203(90), 174(100), 160$ (95), $122(98), 103(95)$, 77 (97). HRMS (EI): calcd. for $\mathrm{C}_{17} \mathrm{H}_{16} \mathrm{~N}_{3} \mathrm{OS}^{79} \mathrm{Br}\left[\mathrm{M}^{79} \mathrm{Br}\right]^{+}$ 389.0197; found, 389.0198. FTIR $\left(\nu_{\max }, \mathrm{cm}^{-1}\right): 2987,2932,1671$, and 1599 .

2.5. Preparation of Polymer Films. The polymer matrix used in this study was PVC ( $K$ value $=67$, degree of polymerization $=800$ ) supplied by SABIC (Saudi Arabia). It was reprecipitated from a THF solution (THF is the best solvent for PVC) by alcohol several times and finally dried under vacuum at room temperature for $24 \mathrm{~h}$. PVC films were prepared by dissolving PVC (5 g) in THF (100 g) under vigorous stirring for $30 \mathrm{~min}$. It was necessary to control the hygrometry and the rate of evaporation of solvent during casting to maintain good optical quality and very limited turbidity. The film transmission should be greater than $80 \%$ in the near-UV range. After $3 \mathrm{~h}$, the solution was spread on a slide of stainless steel $(250 \times 120 \times 0.5 \mathrm{~mm})$ and air-dried for $24 \mathrm{~h}$. After the solvent evaporation, the samples were dried in a vacuum at room temperature for $30 \mathrm{~h}$. The thickness of the resulting PVC film $(30 \mu \mathrm{m})$ was measured by a micrometer type 2610 A, Germany.

\subsection{Irradiation Experiments}

2.6.1. Accelerated Testing Technique. A QUV Accelerated Weather Tester (Q-Lab, USA) was used for irradiation of polymers films. The accelerated weathering tester contained a stainless steel plate, which had two holes in the front side and a third one behind. Each side contained a 40 watt fluorescent ultraviolet light. These lamps were of the type UV-B 313, giving a spectrum range between 290 and $360 \mathrm{~nm}$ with a maximum wavelength at $313 \mathrm{~nm}$. The polymer film samples were vertically fixed parallel to the lamps to make sure that the UV incident radiation was perpendicular to the samples. The irradiated samples were rotated from time to time to ensure that the intensity of light incident on all samples was the same.

\subsection{Photodegradation Measuring Methods}

2.7.1. Measuring the Photodegradation Rate of Polymer Films Using Infrared Spectrophotometry. The degree of photodegradation of polymer film samples was followed by monitoring FTIR spectra in the range $4000-400 \mathrm{~cm}^{-1}$ using a Shimadzu FTIR 8300 spectrophotometer. Absorptions due to an alkene group at $1631 \mathrm{~cm}^{-1}$, a carbonyl group at $1724 \mathrm{~cm}^{-1}$, and a hydroxyl group at $3400 \mathrm{~cm}^{-1}$ were specifically monitored. The progress of photodegradation during different irradiation times was followed by observing the changes in these peaks. Then hydroxyl $\left(I_{\mathrm{OH}}\right)$, carbonyl $\left(I_{\mathrm{CO}}\right)$, and polyene $\left(I_{\mathrm{PO}}\right)$ indices were calculated by comparison of these absorption peaks with a reference peak at $1328 \mathrm{~cm}^{-1}$, which is not significantly affected by the degradation process. The method used was the band index method, which includes the following features [16]:

$$
\mathrm{Is}=\frac{\mathrm{As}}{\mathrm{Ar}} \text {. }
$$

As = absorbance of peak under study, Ar = absorbance of reference peak, and Is = index of group under study.

Actual absorbance, the difference between the absorbance of top of peak and base line (A Top of Peak - A Base Line), is calculated using the base line method [16].

2.8. Determination of Average Molecular Weight $\left(\bar{M}_{v}\right)$ Using Viscometry. The viscosity property was used to determine the average molecular weight of polymer, using the Mark Houwink relation [17]:

$$
[\eta]=K \bar{M}_{v}^{\alpha}
$$




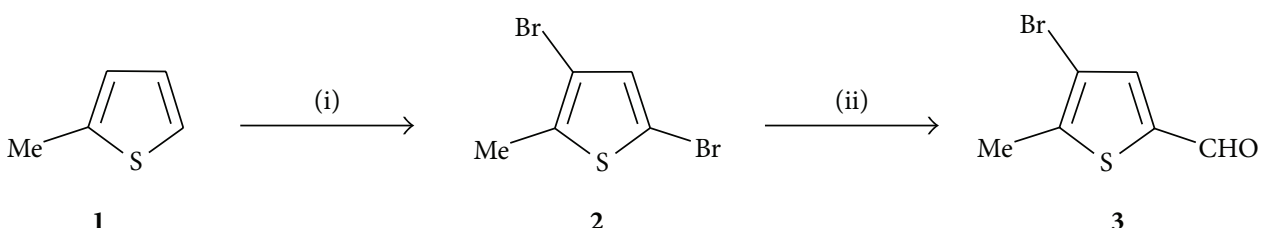

Reagents and conditions: (i) $\mathrm{Br}_{2} / \mathrm{AcOH}, 0^{\circ} \mathrm{C}, 16 \mathrm{~h}$ (95\%). (ii) $n$-BuLi (1 equiv.), THF,

$-78^{\circ} \mathrm{C}, 30 \mathrm{~min}$, then DMF, RT, $16 \mathrm{~h}, \mathrm{Na}_{2} \mathrm{CO}_{3}(90 \%)$

SCHeme 1: Synthesis of 3-bromo-2-methylthiophene-5-carboxaldehyde (3).

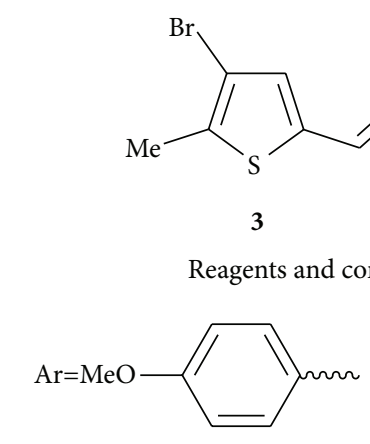

$4 a-e$ (4a)<smiles>Cc1nc2ccccc2c(=O)n1C</smiles>

(4d)

a)

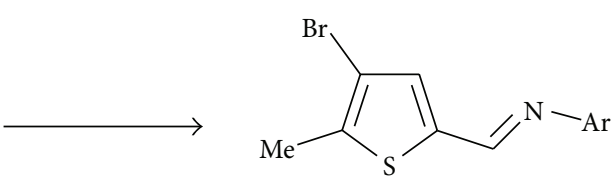

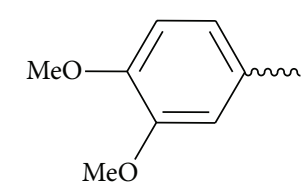

(4b)

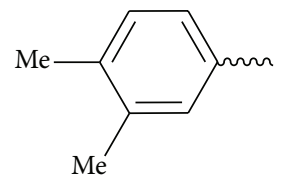

$(4 c)$<smiles>CCCc1nc2ccccc2c(=O)n1C</smiles>

(4e)

SCHeme 2: Synthesis of imines $\mathbf{4 a - e .}$

where $[\eta]=$ the intrinsic viscosity and $K$ and $\alpha$ are constants that depend upon the polymer-solvent system at a particular temperature. The intrinsic viscosity of a polymer solution was measured with an Ostwald U-tube Viscometer. Solutions were made by dissolving the polymer in a solvent $(0.2 \mathrm{~g} / 100 \mathrm{~mL})$ and the flow times of polymer solution and pure solvent are $t$ and $t_{o}$, respectively. Specific viscosity $\left(\eta_{\mathrm{sp}}\right)$ was calculated as follows:

$$
\eta_{\mathrm{rel}}=\frac{t}{t_{o}}
$$

where $\eta_{\text {rel }}=$ relative viscosity

$$
\eta_{\mathrm{sp}}=\eta_{\mathrm{rel}}-1
$$

The single-point measurements were converted to intrinsic viscosities by the following relationship:

$$
[\eta]=\left(\frac{\sqrt{2}}{C}\right)\left(\eta_{\mathrm{sp}}-\ln \eta_{\mathrm{rel}}\right)^{1 / 2}
$$

where $C$ = concentration of polymer solution $(\mathrm{g} / 100 \mathrm{~mL})$.
Molecular weights of PVC with and without additives were calculated from intrinsic viscosities measured in THF solution using the following equation:

$$
[\eta]=1.38 \times 10^{-4} M v^{0.77} \text {. }
$$

The quantum yield of main chain scission $\left(\Phi_{c s}\right)[18]$ was calculated from viscosity measurement using the following relationship:

$$
\phi_{\mathrm{cs}}=\left(\frac{C A}{\bar{M}_{v, 0}}\right) \frac{\left\lfloor\left(\left[\eta_{o}\right] /[\eta]\right)^{1 / \alpha}-1\right\rfloor}{I_{o} t},
$$

where $C=$ concentration; $A=$ Avogadro's number; $\left(\bar{M}_{v, 0}\right)$ $=$ the initial viscosity - average molecular weight; $\left[\eta_{o}\right]=$ intrinsic viscosity of PVC before irradiation; $I_{o}=$ incident intensity $\left(1.052 \times 10^{-8} \mathrm{ein}^{-3} \mathrm{~s}^{-1}\right)$; and $t=$ irradiation time in seconds.

\section{Results and Discussion}

3.1. Synthesis of the Target Imines $\mathbf{4 a - e}$. The target imines (4; Schiff bases) were synthesized by the condensation reactions of 3-bromo-2-methylthiophene-5-carboxaldehyde (3) 


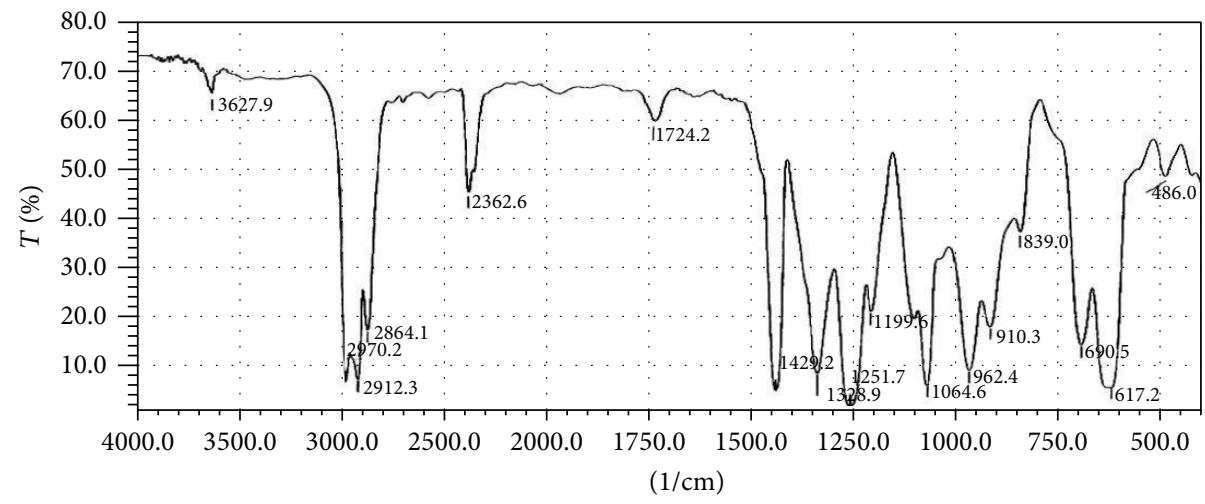

FIGURE 1: FTIR spectrum of PVC film (control) $(30 \mu \mathrm{m})$ at zero time.

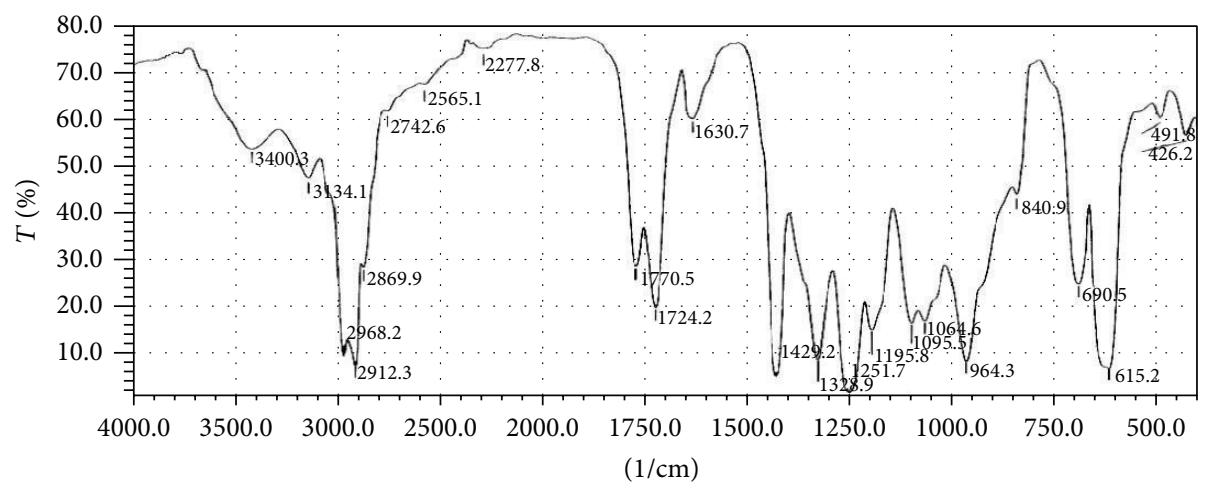

FIGURE 2: FTIR spectrum of PVC film (control; $30 \mu \mathrm{m}$ ) after 250 hours.

with the appropriate amine. The required aldehyde 3 was synthesized from 3-methylthiophene (1) in two steps. The first one involved bromination of $\mathbf{1}$ to give 3,5-dibromo2-methylthiophene (2) which was then converted to the aldehyde 3 in the second step by selective bromine-lithium exchange of the $\alpha$-bromo group, followed by treatment with dimethylformamide (DMF) as shown in Scheme 1.

For the synthesis of the target imines 4 , aldehyde 3 (1 molar equivalent) was allowed to react with various amines, namely, 4-methoxyaniline, 3,4-dimethoxyaniline, 3,4-dimethylaniline, 3-amino-2-methylquinazolin-4(3H)-one, and 3-amino-2-isopropylquinazolin-4(3H)-one (Scheme 2). Reactions were carried out under microwave irradiation for $5 \mathrm{~min}$ in absolute methanol. The solvent was removed and the crude products were recrystallized to give pure imines 4 in high yields. The structures of the synthesized imines 4a-e were confirmed by FTIR, ${ }^{1} \mathrm{H}$ NMR, and ${ }^{13} \mathrm{C}$ NMR spectroscopy and by mass spectrometry (EI-MS and HRMS).

The FTIR spectra of $4 a-e$ showed the presence of a characteristic band for the $\mathrm{C}=\mathrm{N}$ stretching vibration within the $1599-1615 \mathrm{~cm}^{-1}$ region. The ${ }^{1} \mathrm{H}$ NMR spectra showed a characteristic singlet signal at $\delta=8.34-9.15 \mathrm{ppm}$ corresponding to $\mathrm{H}-\mathrm{C}=\mathrm{N}$. The structures of $\mathbf{4 a}-\mathbf{e}$ were confirmed further by EI-mass spectrometry, which showed the presence of molecular ion peaks, the elemental compositions of which were proved by high resolution mass spectrometry (HRMS). See Section 2 for details.
3.2. Photostabilization Study. Compounds $4 \mathbf{4 a - e}$ were used as additives for the photostabilization of PVC films. In order to study the photochemical activity of these additives for the photostabilization of PVC films; the carbonyl and alkene indices were monitored as a function of irradiation time using IR spectrophotometry. The irradiation of PVC films with UV light of wavelength, $\lambda=313 \mathrm{~nm}$, led to a clear change in their FTIR spectra, as shown in the FTIR spectra of the PVC before (Figure 1) and after (Figure 2) irradiation. Appearance of bands at $1770 \mathrm{~cm}^{-1}$ and $1724 \mathrm{~cm}^{-1}$ was attributed to the formation of carbonyl groups related to chloroketone and to aliphatic ketone, respectively. A third band was observed at $1631 \mathrm{~cm}^{-1}$, which implied formation of a $\mathrm{C}=\mathrm{C}$ double bond conjugated to a carbonyl group. The hydroxyl band that appeared at $3400 \mathrm{~cm}^{-1}$ was attributed to the $\mathrm{OH}$ of the hydroperoxide and alcohol groups, as shown in Scheme 3 $[16,19]$.

The changes in the intensities of the stretching absorption bands of the hydroxyl, carbonyl, and alkene groups were used to follow the extent of polymer degradation during irradiation, because the intensities of these bands are directly proportional to the extent of degradation [11]. The degradation was calculated in terms of the hydroxyl index $\left(I_{\mathrm{OH}}\right.$, as $\mathrm{OH}$ formation indicator), carbonyl index $\left(I_{\mathrm{CO}}\right.$, as $\mathrm{C}=\mathrm{O}$ formation indicator $)$, and polyene index $\left(I_{\mathrm{PO}}\right.$, as $\mathrm{C}=\mathrm{C}$ formation indicator). Figure 3 shows the effects of adding the new imines $4 \mathbf{a}-\mathbf{e}$ to the PVC ( $0.5 \%$ by weight) on the growth 


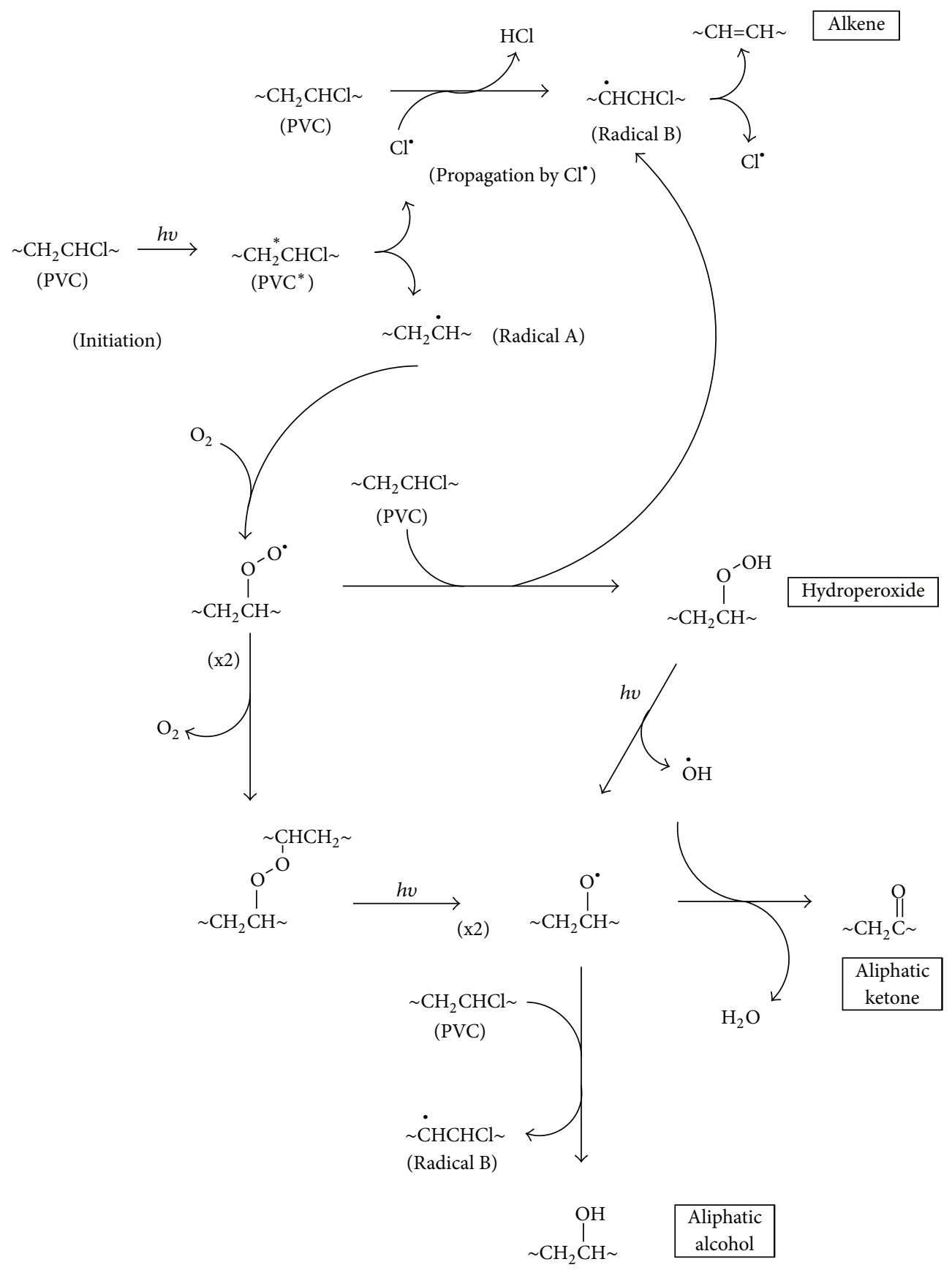

Scheme 3: Some of the photooxidation processes of PVC: reactions of radical B with molecular oxygen, akin to those of radical A, would give rise to chloroketone, chloroalcohol, and chlorohydroperoxide moieties; further reactions of such reactive functionalities may lead to chain cleavage and reduction in molecular weight.

of the $I_{\mathrm{CO}}$, which reflects the extent of degradation of the PVC. It is clear that the addition of any of the compounds 4a-e lowered the growth of the carbonyl index of the PVC in comparison with the control sample. So, it is reasonable to conclude that these additives might be considered as photostabilizers of PVC polymer.

Since an efficient photostabilizer shows a longer induction period, compound $\mathbf{4 e}$ is considered as the most active photostabilizer, followed by $\mathbf{4 d}, \mathbf{4 b}, \mathbf{4 a}$, and $\mathbf{4 c}$. Just as formation of carbonyl groups indicates degradation of polymer, so does the formation of alkene units. Therefore, the polyene index $\left(I_{\mathrm{PO}}\right)$ was also monitored with irradiation time in the presence of each of $4 a-e$. As shown in Figure 4 the results are comparable with those of the effect on the $I_{\mathrm{CO}}$; compounds 4a-e showed the same order in their efficiency at reducing the growth of $I_{\mathrm{PO}}$.

The hydroxyl index $\left(I_{\mathrm{OH}}\right)$ growth versus irradiation time was also monitored for the PVC in the presence of each of compounds $4 a-e$ against the pure PVC. All of the compounds 4a-e showed a positive effect by lowering the growth of the 


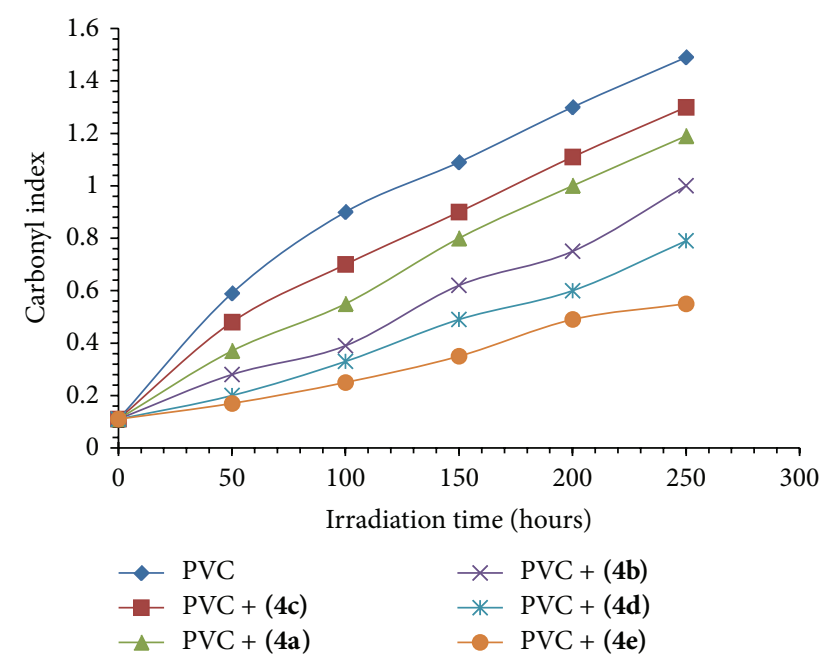

FIGURE 3: The relationship between the carbonyl index and irradiation time for PVC films ( $30 \mu \mathrm{m}$ thickness) containing each of $\mathbf{4 a -}$ e ( $0.5 \%$ by weight) compared to PVC without additive (blank).

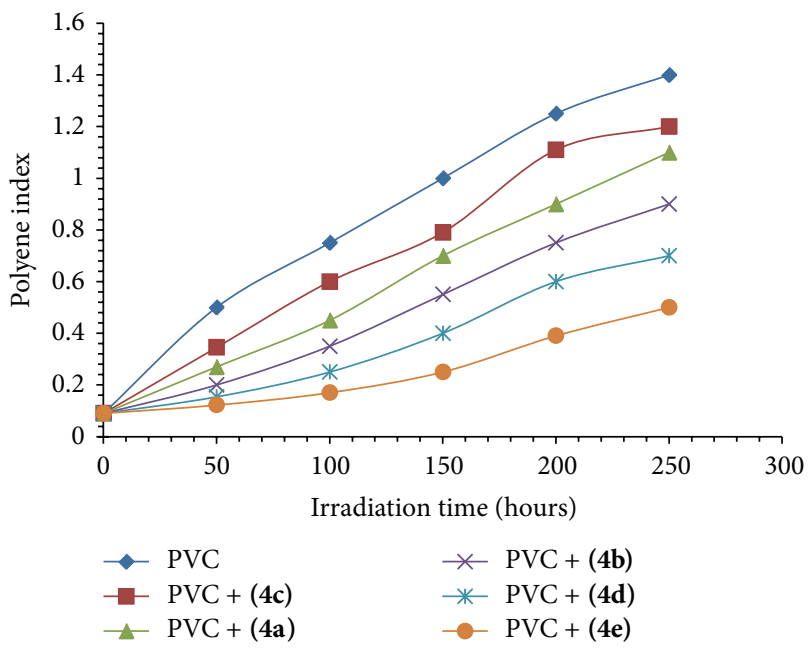

FIGURE 4: The relationship between the alkene index and irradiation time for PVC films ( $30 \mu \mathrm{m}$ thickness) with or without additives $4 \mathbf{a}-\mathbf{e}$ ( $0.5 \%$ by weight).

hydroxyl index in the same order of efficiency as for both $I_{\mathrm{CO}}$ and $I_{\mathrm{PO}}$ (Figure 5).

\subsection{Variation of PVC Molecular Weight during Photolysis} in the Presence of $\mathbf{4 a}-\boldsymbol{e}$. The photodegradation of polymers causes changes in viscosity average molecular weight $\left(\bar{M}_{v}\right)$ [20]. Accordingly, we decided to monitor the photodegradation process by monitoring the change in $\bar{M}_{v}$ and other parameters that are related to it, particularly the average number of chain scissions (average number of cuts per single chain) $(N)$ and the quantum yield of the chain scission process $\left(\Phi_{\mathrm{cs}}\right)$.

Figure 6 shows the change of the $\bar{M}_{v}$ values with the irradiation time for PVC films in the presence of each of the selected additives $4 \mathbf{a}-\mathbf{e}$ 0.5\% (wt/wt) and for the pure PVC

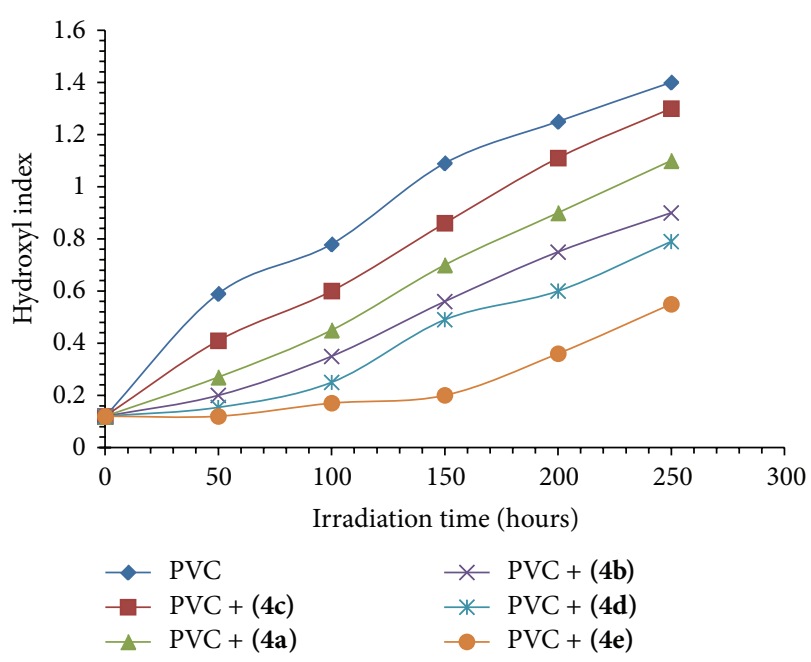

FIGURE 5: The relationship between the hydroxyl index and irradiation time for PVC films ( $30 \mu \mathrm{m}$ thickness) with or without $4 \mathbf{a}-\mathbf{e}$ ( $0.5 \%$ by weight $)$.

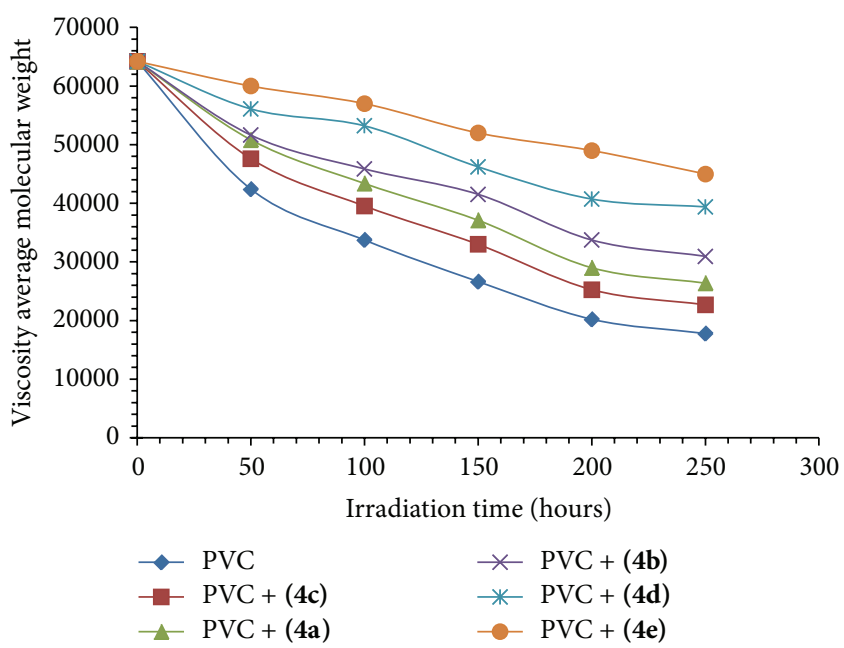

FIgURE 6: Changes in the viscosity-average molecular weight $\left(\bar{M}_{v}\right)$ during irradiation of PVC films $(30 \mu \mathrm{m})$ with or without $4 \mathbf{a}-\mathbf{e}(0.5 \%$ by weight).

as control $\left(\bar{M}_{v}\right.$ was calculated using (2) with THF as solvent at $25^{\circ} \mathrm{C}$ ). It is clear that addition of $\mathbf{4 a}-\mathbf{e}$ to the PVC films reduces the decrease in the $\bar{M}_{v}$ which means that the additives inhibit the photodegradation process and stabilize the PVC. Again the efficiencies of $\mathbf{4 a - e}$ were in the same order found in the previous tests.

Chain scissions occur as a result of photodegradation of polymers and increase in number with increasing irradiation time. Therefore, the average number of chain scissions (average number of cuts per single chain) $(N)[20,21]$, calculated using (8), is used to monitor photodegradation. Consider

$$
N=\frac{\overline{M_{v, 0}}}{\overline{M_{v, t}}}-1
$$




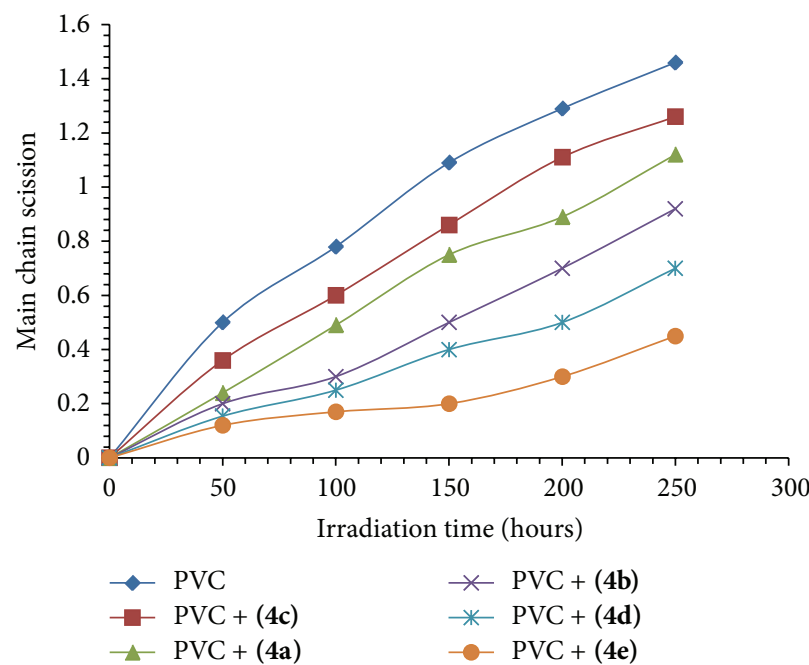

Figure 7: Changes in chain scission $(N)$ during irradiation of PVC films $(30 \mu \mathrm{m})$ containing $4 \mathbf{a}-\mathbf{e}(0.5 \%$ by weight $)$ or no additive.<smiles>CCCc1nc2ccccc2c(=O)n1N=Cc1cc(Br)c(C)s1</smiles><smiles>CCCc1nc2ccccc2c(=O)n1N=Cc1cc(Br)c(C)s1</smiles>

Scheme 4: A suggested mechanism of photostabilization of PVC by $\mathbf{4 e}$ through absorption of UV light and dissipation of the light energy as heat.

To study the effect on its stability of adding compounds 4a-e to the PVC, the values of the average number of chain scissions $N$ were calculated at the irradiation time intervals that were used in this study. The plot of $N$ versus irradiation time is shown in Figure 7, which shows that the growth of the value of the chain scissions in the presence of $\mathbf{4 a - e}$ follows the same trend as the decrease in molecular weight.

Finally, the change in the quantum yield of main chain scission $\left(\phi_{c s}\right)$ was studied. After $250 \mathrm{~h}$ of irradiation the $\phi_{c s}$ was calculated using (7) for the PVC films with and without $0.5 \%$ (wt/wt) of compounds $\mathbf{4 a - e}$ (Table 1 ).

The $\Phi_{\mathrm{cs}}$ values for PVC films in the presence of additive were of course less than that of pure PVC (control), and the values increased in the following order: $\mathbf{4 e}<\mathbf{4 d}<\mathbf{4 b}$ $<\mathbf{4 a}<\mathbf{4 c}$. The explanation for low value of $\Phi_{\mathrm{cs}}$ of PVC (control) is that, in the macromolecules of PVC, the energy is absorbed at one site, and then the electronic excitation is distributed over many bonds so that the probability of a single bond breaking is small, or the absorbed energy is dissipated by nonreactive processes. However, the additives caused a further reduction of around 1000-fold in the value of $\Phi_{c s}$, which is comparable with the reduction brought about by use of salicylidene imines of substituted aminothiadiazoles [22].

It is well established that the quantum yield $\left(\Phi_{\text {cS }}\right)$ increases with increasing temperature [23] around the glass transition temperature ( $\mathrm{Tg}$ ) of amorphous polymers and around the melting temperature of crystalline polymers. In the study presented in this work, the photolysis of PVC film was carried out at a temperature $35-45^{\circ} \mathrm{C}$, well below the glass transition temperature $\left(\mathrm{Tg}\right.$ of $\left.\mathrm{PVC}=80^{\circ} \mathrm{C}\right)$. Therefore, 


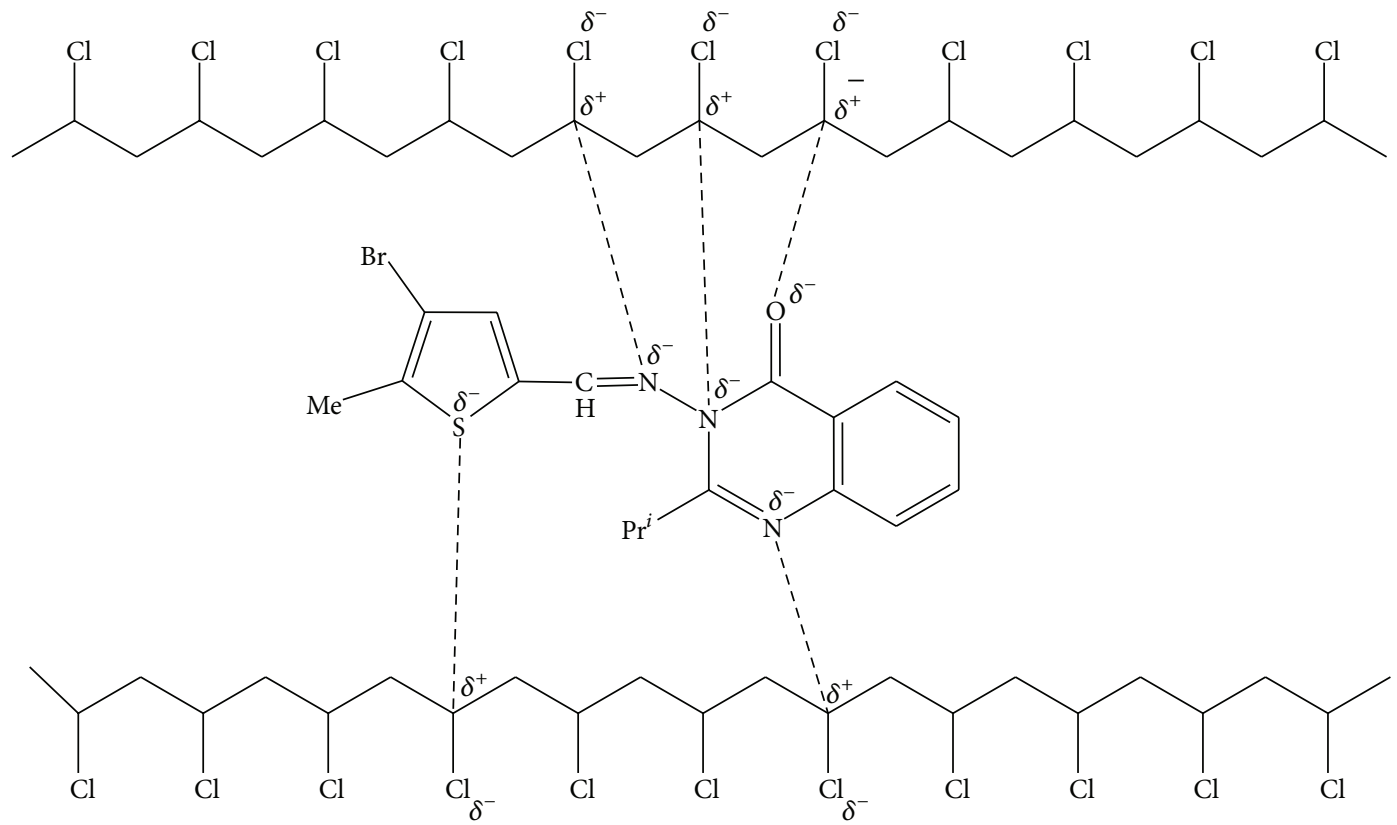

Scheme 5: A suggested mechanism of photostabilization of PVC by $\mathbf{4 e}$ through interaction between the polymer chains and Schiff base compounds, leading to more effective energy transfer.

TABLE 1: Quantum yield $\left(\Phi_{\mathrm{cs}}\right)$ for chain scission for PVC films $(30 \mu \mathrm{m})$ with and without additive $(0.5 \% \mathrm{wt})$ after $250 \mathrm{~h}$ irradiation time.

\begin{tabular}{lc}
\hline Additive $(0.5 \% \mathrm{wt})$ & Quantum yield of main chain scission $\left(\Phi_{\mathrm{cs}}\right)$ \\
\hline $\mathrm{PVC}+\mathbf{4 e}$ & $4.83 E-08$ \\
$\mathrm{PVC}+\mathbf{4 d}$ & $5.97 E-08$ \\
$\mathrm{PVC}+\mathbf{4 b}$ & $6.55 E-08$ \\
$\mathrm{PVC}+\mathbf{4 a}$ & $7.09 E-08$ \\
$\mathrm{PVC}+\mathbf{4 c}$ & $7.79 E-08$ \\
$\mathrm{PVC}$ (blank) & $8.34 E-05$ \\
\hline
\end{tabular}

dependency of $\Phi_{\mathrm{cs}}$ on temperature was not expected to be significant.

3.4. Suggested Mechanisms of Photostabilization of PVC by 3-[(3-Bromo-2-methylthiophen-5-yl)methyleneamino]-2isopropylquinazolin-4(3H)-one (4e). The efficiency of the new compounds $\mathbf{4 a - e}$ as photostabilizers for PVC films decreases in the order $\mathbf{4 e}>\mathbf{4 d}>\mathbf{4 b}>\mathbf{4 a}>\mathbf{4 c}$. These compounds may stabilize PVC by direct absorption of UV radiation and dissipation of the energy as heat (Scheme 4).

Thiophene moieties themselves may also be able to act in a similar way to absorb UV radiation and to dissipate the energy as heat, but obviously the nature of the nitrogen substituent on the imine group had a significant effect on the efficiency of the additives as stabilizers so any direct effect of the thiophene ring alone is likely to be minor. The polarity of the thiophene ring may also lead to attraction between the stabilizer and PVC, which again would be influenced by the nature of the nitrogen substituent on the imine group, as shown for additive $4 \mathrm{e}$ in Scheme 5 . Such attraction may assist transfer of energy from excited state PVC to the additive, from where it can be dissipated. The observed trends may help in the design of even better photostabilizers for PVC.

\section{Conclusion}

New thiophene derivatives $\mathbf{4 a}-\mathbf{e}$ incorporating an imine group have been successfully synthesized and characterized. The level of photodegradation of (PVC) films containing the synthesized thiophenes $(0.5 \%$; by weight) was reduced in all cases, with effectiveness of the additives in the order $\mathbf{4 e}>\mathbf{4 d}>\mathbf{4 b}>\mathbf{4 a}>\mathbf{4 c}$. For the most favorable additive (4e), the rate of appearance of infrared absorption bands of degradation products was reduced by around two-thirds, while the quantum yield of chain scission was calculated to be reduced by a factor of more than one thousand.

It is suggested that the additives may help stabilize PVC by direct absorption of UV radiation and dissipation of the energy as heat, or that electrostatic attraction between the additives and PVC may assist transfer of energy from excited state PVC to the additive, from where it can be dissipated.

\section{Conflict of Interests}

The authors declare that there is no conflict of interests regarding the publication of this paper.

\section{Acknowledgment}

The authors extend their appreciation to the Deanship of Scientific Research at King Saud University for its funding for this research through the research group Project RGP-VPP239. 


\section{References}

[1] M. Saeedi, I. Ghasemi, and M. Karrabi, “Thermal degradation of poly(vinyl chloride): effect of nanoclay and low density polyethylene content," Iranian Polymer Journal, vol. 20, no. 5, pp. 423-432, 2011.

[2] E. Yousif, A. Hameed, R. Rashed et al., "Synthesis and photostability study of some modified poly(vinyl chloride) containing pendant benzothiazole and benzimidozole ring," International Journal of Chemistry, vol. 2, no. 1, pp. 65-80, 2010.

[3] J. L. Gardette, S. Gaumet, and J. L. Philippart, "Influence of the experimental conditions on the photooxidation of poly(vinyl chloride)," Journal of Applied Polymer Science, vol. 48, no. 11, pp. 1885-1895, 1993.

[4] J. Gao, J. Yang, Y. Du, and X. Liu, "Dynamic rheological behavior and mechanical properties of PVC/ACS blends," Iranian Polymer Journal, vol. 22, no. 4, pp. 285-292, 2013.

[5] P. Kadam, R. Kute, and S. Mhaske, "Effect of nano-alumina concentration on the properties of poly(vinyl chloride)/thermoplastic polyester elastomer blend system," Iranian Polymer Journal, vol. 22, no. 8, pp. 549-560, 2013.

[6] H. Shi, X. Liu, and Y. Zhang, "Fabrication of novel antimicrobial poly(vinyl chloride) plastic for automobile interior applications," Iranian Polymer Journal, vol. 23, no. 4, pp. 297-305, 2014.

[7] J. M. Hankett, W. R. Collin, and Z. Chen, "Molecular structural changes of plasticized PVC after UV light exposure," Journal of Physical Chemistry B, vol. 117, no. 50, pp. 16336-16344, 2013.

[8] K. Smith, A. A. Balakit, and G. A. El-Hiti, "Poly(propylene sulfide)-borane: convenient and versatile reagent for organic synthesis," Tetrahedron, vol. 68, no. 38, pp. 7834-7839, 2012.

[9] K. Smith, G. A. El-Hiti, and M. B. Alshammari, "Directed lithiation of $N^{\prime}$-[2-(4-methoxyphenyl)ethyl]-N, N-dimethylurea and tert-butyl [2-(4-methoxyphenyl)ethyl]carbamate," Synthesis, vol. 46, no. 3, Article ID SS-2013-Z0717-OP, pp. 394-402, 2014.

[10] Y. Sert, A. A. Balakit, N. Öztürk, F. Ucun, and G. A. El-Hiti, "Experimental (FT-IR, NMR and UV) and theoretical (M06$2 \mathrm{X}$ and DFT) investigation, and frequency estimation analyses on (E)-3-(4-bromo-5- methylthiophen-2-yl)acrylonitrile," Spectrochimica Acta Part A, vol. 131, pp. 502-511, 2014.

[11] E. Yousif, J. Salimon, N. Salih, A. Jawad, and Y.-F. Win, "New stabilizers for PVC based on some diorganotin(IV) complexes with benzamidoleucine," Arabian Journal of Chemistry, 2012.

[12] B. S. Furniss, A. J. Hannaford, P. W. G. Smith, and A. R. Tatchell, Vogel's Textbook of Practical Organic Chemistry, Longman, Harlow, UK, 5th edition, 1989.

[13] S. C. Watson and J. F. Eastham, "Colored indicators for simple direct titration of magnesium and lithium reagents," Journal of Organometallic Chemistry, vol. 9, no. 1, pp. 165-168, 1967.

[14] S. Pu, C. Fan, W. Miao, and G. Liu, "The effect of substituent position upon unsymmetrical isomeric diarylethenes bearing a methoxy group," Dyes and Pigments, vol. 84, no. 1, pp. 25-35, 2010.

[15] N. S. Devi, S. J. Singh, and O. M. Singh, "An efficient transesterification of $\beta$-oxodithioesters catalyzed by stannous chloride under solvent-free conditions," Tetrahedron Letters, vol. 54, no. 11, pp. 1432-1435, 2013.

[16] J. Rabek and B. Ranby, Photodegradation, Photooxidation and Photostabilization of Polymers, John Wiley \& Sons, New York, NY, USA, 1975.

[17] J. Mark, Physical Properties of Polymers Handbook, Springer, New York, NY, USA, 2007.
[18] N. Nakajima, M. R. Sadeghi, and T. Kyu, "Swelling of PVC particles during gelation and fusion of plastisols as observed with small-angle light scattering," Journal of Applied Polymer Science, vol. 41, no. 5-6, pp. 889-899, 1990.

[19] A. L. Andrady and N. D. Searle, "Photodegradation of rigid PVC formulations. II. Spectral sensitivity to light-induced yellowing by polychromatic light," Journal of Applied Polymer Science, vol. 37, no. 10, pp. 2789-2802, 1989.

[20] G. Geuskens, "Photodegradation of polymers," in Comprehensive Chemical Kinetics, R. G. Compton, C. H. Bamford, and C. F. H. Tipper, Eds., vol. 14 of Degradation of Polymers, chapter 3, pp. 333-424, Elsevier, Amsterdam, The Netherlands, 1975.

[21] A. V. Shyichuk and J. R. White, "Analysis of chain-scission and crosslinking rates in the photo-oxidation of polystyrene," Journal of Applied Polymer Science, vol. 77, no. 13, pp. 3015-3023, 2000.

[22] E. Yousif, N. Salih, and J. Salimon, "Improvement of the photostabilization of PVC films in the presence of $2 \mathrm{~N}$-salicylidene5-(substituted)-1,3, 4-thiadiazole," Journal of Applied Polymer Science, vol. 120, no. 4, pp. 2207-2214, 2011.

[23] E. A. Yousif, S. M. Aliwi, A. A. Ameer, and J. R. Ukal, "Improved photostability of PVC films in the presence of 2-thioacetic acid-5-phenyl-1,3,4-oxadiazole complexes," Turkish Journal of Chemistry, vol. 33, no. 3, pp. 399-410, 2009. 

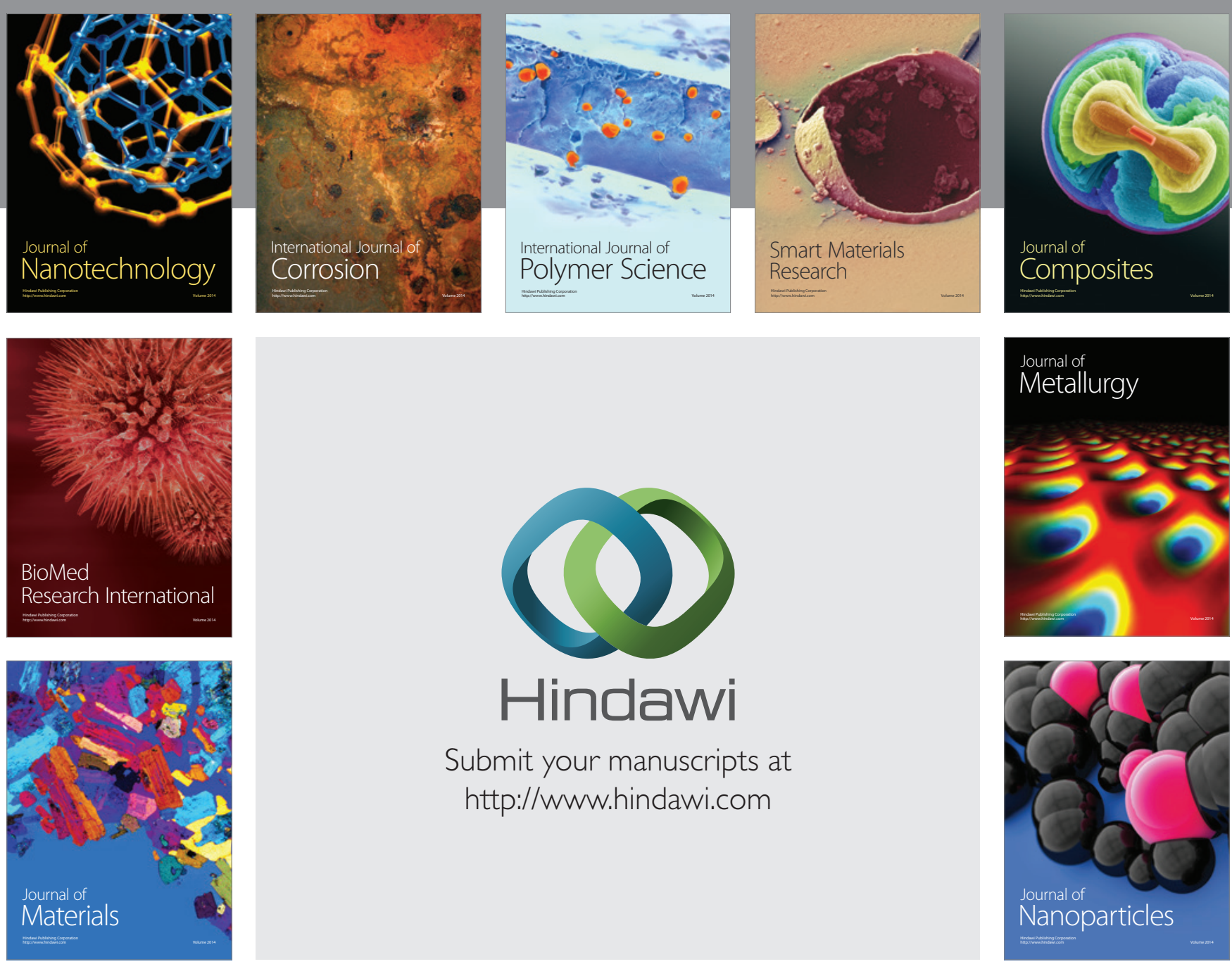

Submit your manuscripts at http://www.hindawi.com
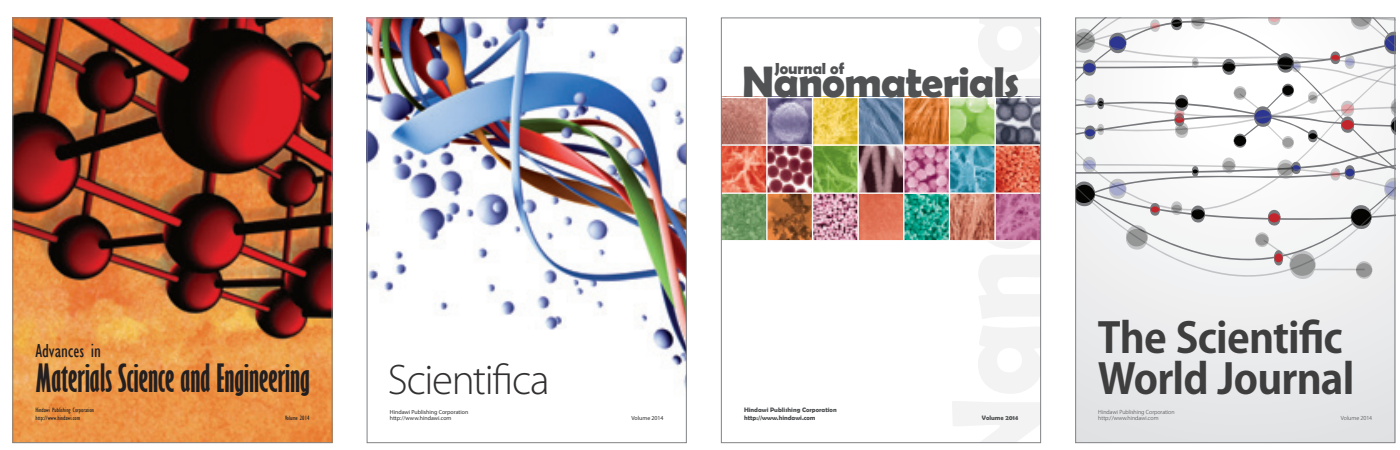

\section{The Scientific World Journal}
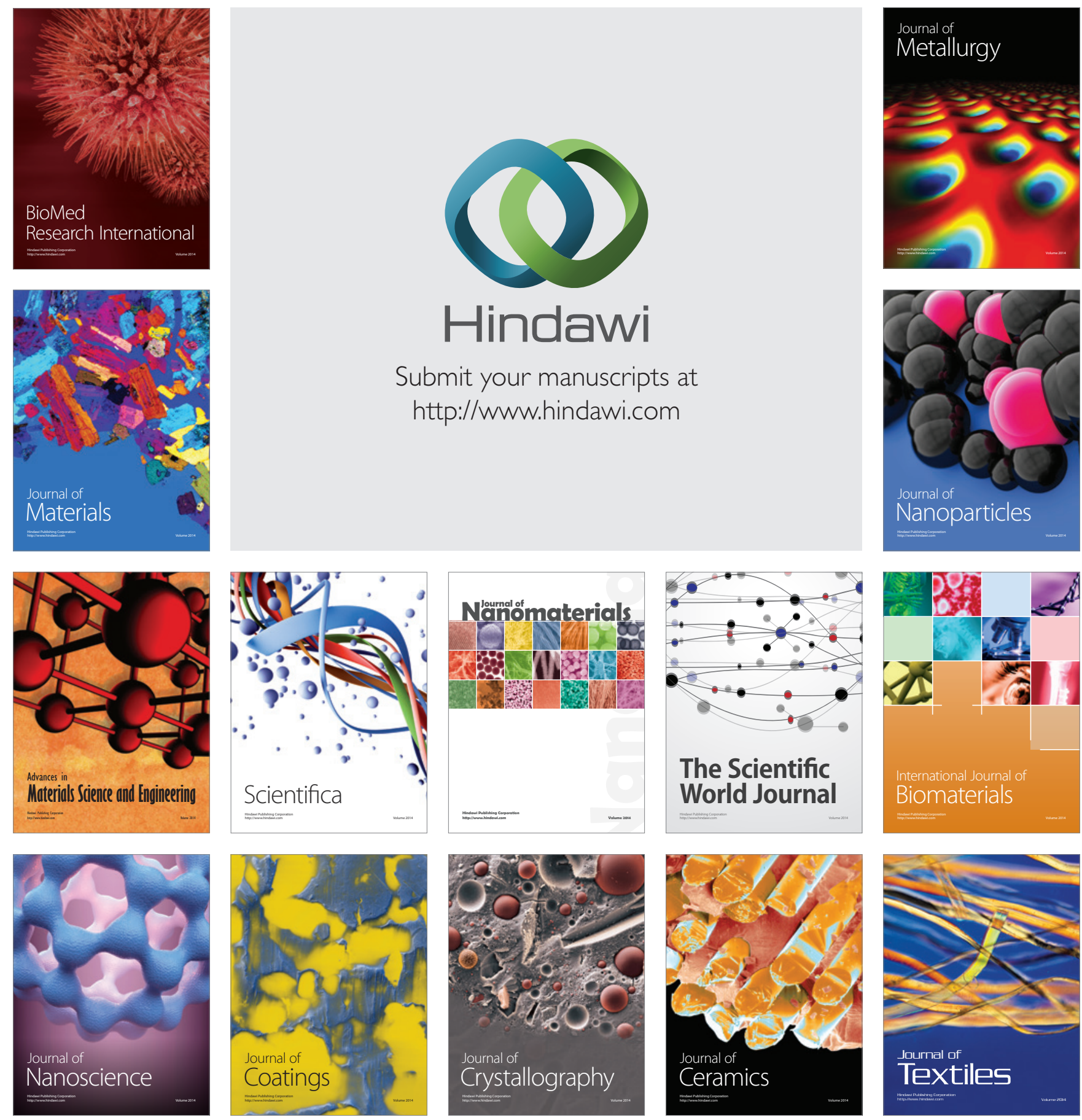